\title{
Development of Tridharma Academic Service Model in Universitas Negeri Gorontalo
}

\author{
Ismet Sulila $^{1}$, Tineke Wolok ${ }^{2}$ \\ \{ismet.sulila@gmail.com $\left.{ }^{1}\right\}$ \\ Universitas Negeri Gorontalo ${ }^{1,2}$
}

\begin{abstract}
Development of Tri Dharma Academic services model was carried out through implementation of public service dimension in Universitas Negeri Gorontalo (Gorontalo State University, henceforth will be called as UNG). It was carried out to comprehensively and holistically study the current model of service and how this model could be further developed to meet the demand of academic service professionalism and also to meet the demand of the students for effective and efficient academic service. The first stage of this study has comprehensively and holistically studied the current academic service model in UNG. The expected result from this initial stage of research was to produce a comprehensive understanding of the current academic service model. The second stage of this study was intended to conduct a study on the model of academic service that suitable with the demand of the academic service users through implementation of public service dimensions and improvement of theservice model.This study aimed at developing a model of academic service that could take into consideration various aspects of a better quality academic service model in UNG. This study was expected to positively contribute to the innovation of academic service which considered quality assurance as for the mainpillar of governance in UNG, in addition to other pillars such as, soft skills, environment, and IT.
\end{abstract}

Keywords. Academic service, Quality Assurance

\section{Introduction}

Higher education has strategic roles in a nation's education. Various science and technology innovations almost always rooted from higher education institution. Higher education policy is focused on Tri Dharma Academic which consists of teaching and learning, research, and community outreach. The enormous expectation on the role of higher education requires these institutions to be able to meet this challenges and expectations in improving the state's education. In order to be able to deliver this expectation, each higher education institution is authorized to create various policies that would accelerate the achievement of their objectives, short-term, mid-term or long-term objectives.

UNG as the largest university in Gorontalo tends to have an increasing number of students over time. In 2017, this university had more than 20, 000 students distributed in 10 faculties. With this large number of students, the demand for efficient and qualified Tri Dharma academic services is necessary. To be able to meet this demand, this university has established four pillars in support the institution governance namely: 1) quality assurance, 2) soft skill, 3) 
environment, 4) information technology. These four pillars have been implemented for the last eight years. However, the reality shows that various efforts to improve the governance of university in order to achieve its vision, to become a leading university.

Based on the result of the initial year study, which concluded that innovation on quality assurance-based academic service model could be developed and carried out through the implementation of public service dimension in higher education Tri [1], [2]. Therefore, the second-year study has to be focused on achieving the ultimate goal of creating a model of effective and efficient tri dharma academic service which based on quality assurance in UNG. This second-year study was important due to the following considerations: 1) to meet the demand for good academic services from the service users such as, students, lecturers, government, community, and other related stakeholders; 2) to keep up with the growing numbers of students in UNG; 3) to anticipate the establishment of other tri dharma academic service supporting units in UNG.

Based on the background described above, this second-year study was focused on the following issues:

1). How was the synergy of units within academic service governance in UNG?

2). What efforts could be done toward the factors that determine the academic service in UNG?

3). How was the development of effective and efficient academic service model which based on quality assurance in UNG?

\section{Methodology}

Research Based on the result of the initial year study and the focus of the second year study, several research methods would be appropriate for this study, such as survey [3], experimental [1] and qualitative-quantitative research and development [4]. This study would be conducted at UNG. This site was selected based on the issues that would be explored, the synergy of units in UNG, actions toward various factors that determined the effectiveness of academic service, and the modeling of academic service based on quality assurance. This study was implemented for six months. The data used in this study were primary and secondary data. The data were collected through, 1) observation, 2) in-depth interview, and 3) field documentation. Further, the data were descriptively analyzed. This descriptive analysis was intended to describe various crucial issues in among various units' synergy, quality assurance, and implementation of the quality assurance-based academic service model in UNG as parts of the efforts to achieve the institution vision and mission, to become a leading university. Further, as Miles, Huberman and Saldana [5] described that in qualitative data analysis there were three simultaneous activities, data condensation, data display, and conclusion drawing/verification.

\section{Result and Discussion}

The field study on three focus of this study has revealed on the following things:

\subsection{Synergy of units in academic service governance in $U N G$}

In 2017, there were ten faculties in UNG with 20,000 students. The growing numbers of working units in UNG such as faculties, departments, and other academic supporting units have been due to the growing demand for knowledge development. However, based on this 
study, there were several aspects that should have been taken into consideration in the establishment of the new units, such as:

a) Institutional Aspect.

UNG needed institutional role and capacity building. Establishment and revitalization of the organizational structure either in university, faculty, department, and study program level to meet community demand for higher education, research result, and implementation of science and technology.

b) Job Analysis.

Conduct job analysis to compile an organizational structure and its personnel along with the jobs description and authority. This analysis is expected to be in synergy with the structure of the faculty, department, study program, and institutions, and units in UNG.

c) Openness.

Openness aspect in resources governance in university, faculty, department, study program, institutions and other units within the university is provided to the related stakeholders systematically, accountably, and in observance of the current regulation.

d) Policy aspect.

In order to keep up with current development, university policy review was needed, especially for the regulations that inhibit or unable to accommodate the current and future needs of the university. Therefore, total evaluation on institutional aspect either in education/academic aspect or financial and administrative aspects was also needed. From this review, there would be a synergy in the implementation of organizational administration in UNG.

e) Partnership.

As an institution that provides higher education in the modern world, partnership, cooperation and support from other parties were needed in the efforts to achieve the organization vision and mission. Therefore, current cooperation needed to be maintained and improved for the betterment of the institution. In addition, periodic evaluation on the achievement of university's strategic plan also needs to be done. Preparation of various institutional aspects as well as maintaining and building intensive cooperation and partnership with other higher education institutions, government, business world, and community were also needed.

Based on the focus of the initial year study above, the importance of synergy among units could be turned into an organizational culture within the Universitas Negeri Gorontalo. Organizational culture is defined as the "essence" of an organization because it contained philosophy, vision, and mission of the organization, which in turn would be a strength for an organization to compete in the world [6].

\subsection{Efforts for Academic Factors that Determined the Academic Services in UNG}

The initial year study has revealed various factors that determines the effectiveness and the quality academic services in UNG; thus, the next efforts were to focus on the improvement of human resource capacity, which consisted of:

a) Improvement of lecturers' potential.

The capacity of lecturers in UNG could be improved both from academic capacity, academic echelon, or professionalism. Capacity development for lecturers was expected to be able to ensure that this university level of output met the set quality standard..

b) Improve the capacity of the administrative clerks. 
Academic support staffs were one of the supporting stakeholders in higher education governance. Therefore, it was to be considered as parts of the success in each tri dharma academic services, parts of students' achievement in their study accomplishment, as well as the main agent in administrative functions of a higher education institution. Therefore, the establishment of academic qualification as the basic requirement in administrative position's appointment had to be consistently implemented and supported with education program and training which was developed in both on-site training as well as off-site training, either within the country or abroad.

c) Welfare.

Within the context of welfare, UNG was fully aware that along with the needs to increase the administrative staffs' welfare. Within their strategic planning period, gradually welfare improvement would be distributed to all the staffs and employees at UNG.

This study revealed that lecturers' and academic staffs' capacity improvement and their welfare played an important role in the implementation of four pillars of UNG. This had a significant impact on the success of higher education to achieve its short-term, midterm, and long-term vision and mission. In this context, a specific effort was needed to scientifically study the stages of effective Tri Dharma academic service which based on quality assurance in UNG [7].

\subsection{Development Stages of Effective Academic Service Model Based on Quality Assurance} in Universitas Negeri Gorontalo.

Development of academic service model was focused on comprehensive analysis of the procedure and mechanism of qualified academic services process. The development of this model can help increase the effectiveness of tri dharma academic services which consisted of teaching and learning, research, and community outreach. The academic service procedure was integrated into the four development pillars of UNG. In addition, the academic service model also took into consideration the results of studies in the first and second priority of this study. The development stages of this academic service model were described in Figure 1.

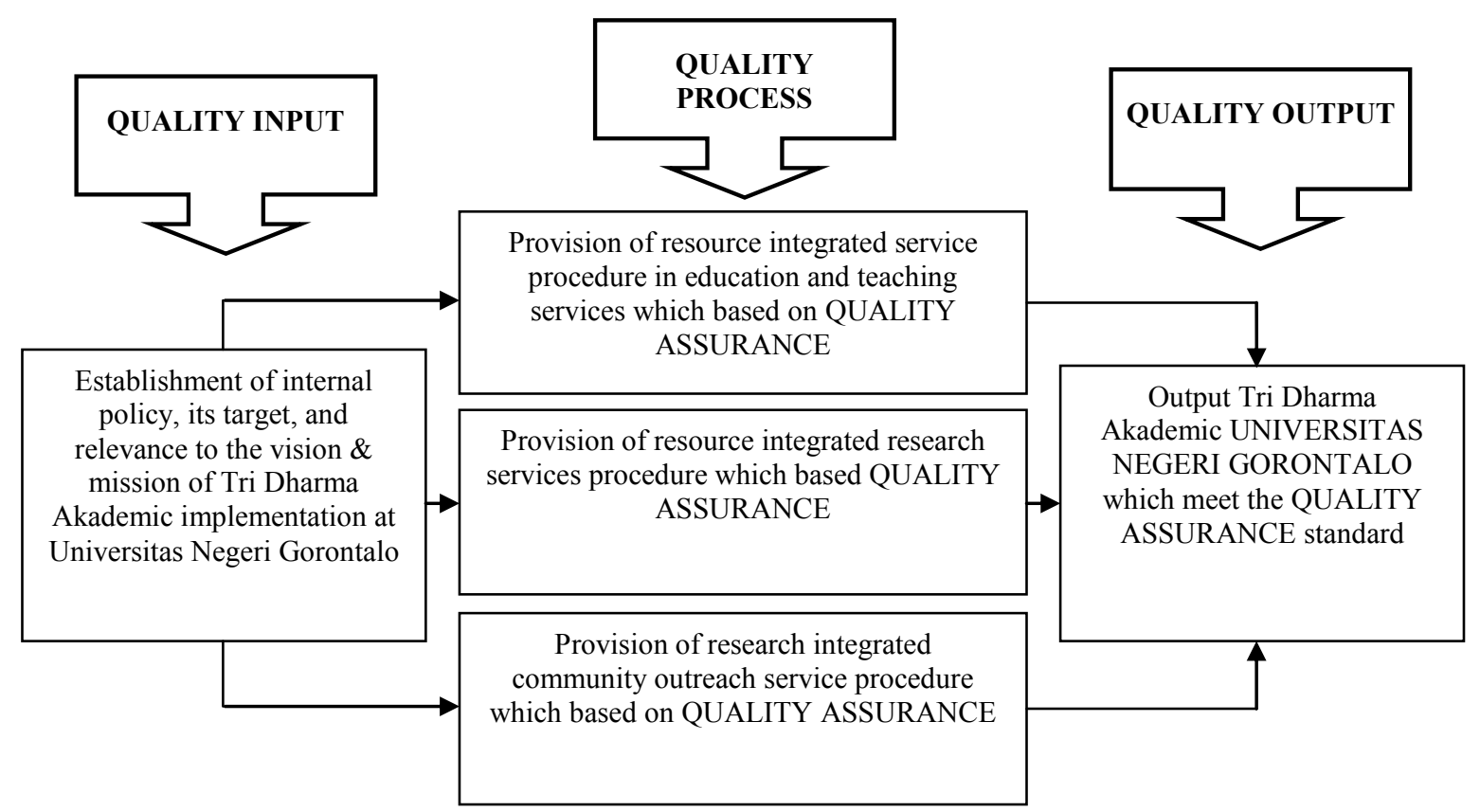

Figure 1. Development Stages of Quality Assurance-Based academic service model 


\section{Conclusion}

The The following things were concluded in this study:

1) The synergy of work units within the management of academic services would be effective when these things are fulfilled: 1) the resources were suitable with need of the work unit, 2) effective communication among units within the university, 3 ) implementation of consistent and sustainable academic regulation related to tri dharma academic, 4) support and commitment of the head of all units and staffs to achieve the tri dharma academic objectives, 5) regular evaluation and improvement of tri dharma academic programs.

2) The efforts that could be taken toward factors that determine the academic services in UNG consisted of 1) provision of academic staffs that suitable with the need of each work unit, study program, and department, 2) provision of academic support staffs in each work units, 3) provision of facilities and infrastructure in all units, 4) strengthening of rector policy related to implementation of tri dharma academic in UNG, 5) strengthening the implementation of the four pillars which are: quality assurance, environment, soft skills, and IT.

3) The development stages of the quality assurance-based academic service model which integrated with other pillars could be implemented in tri dharma academic service of theuniversityin order to create a qualified tri dharma academic services and enhancing the achievement of UNG vision to become a leading university.

\section{References}

[1] Sugiyono, Metode Penelitian Kuantitatif, Kualitatif $R \& D$ [R\&D Qualitative, quantitative research methods]. Bandung: Alfabeta, 2007.

[2] H. A. Wani, "Impact of Globalization on World Culture," Res. J. Humanit. Soc. Sci., vol. 2, no. 2, pp. 33-39, 2011.

[3] S. Faisal, Format-format Penelitian Sosial [Social sciences research formats]. Jakarta: PT. Raja Grafindo Persada, 2005.

[4] Nawaw and Martini, Penelitian Terapan [Applied research]. GadjahMada University Press, 2005.

[5] M. . Miles, A. M. Huberman, and J. Saldana, Qualitative Data Analysis, A Methods Sourcebook, Edition 3. USA:, 3rd ed. London, Depok: Sage Publications,UI-Press., 2014.

[6] K. Angelo and Kreitner, Organizational Behaviour. Irwin: Chicago, 1995.

[7] T. Wolok, "Dimensi quality assurance dalam tri dharma akademik di Universitas Negeri Gorontalo," in Prosiding Seminar Nasional Penelitian dan PKM: Sosial, Ekonomi dan Humaniora[Dimension of quality assurance in academic tri dharma. 